\title{
ENTREPUEBLOS: LA COOPERACIÓN COMO BASE TEÓRICA Y PRÁCTICA DE LA EDUCACIÓN PARA EL DESARROLLO
}

\author{
Entrepueblos - La Rioja
}

La globalización es la nueva palabra de moda acuñada recientemente dentro del sistema neoliberal.

Oímos hablar de cosas como el libre mercado, la aldea global o la moneda única; pero lo cierto es que lo verdaderamente global es el desequilibrio comercial, la prohibición a @ @ pobres de moverse libremente en este mundo de tod@s y una moneda (por fin algo cierto) única: el dólar.

La globalización desfila impecable en la pasarela de los medios, aunque cuidando muy mucho de no mostrar su miseria de camerino.

Los países empobrecidos, en su mayoría, no dejan de ser "top-models" codiciadas en este sentido por muchos diseñadores de lo injusto. Pero en su camerino las flores, provistas de un incansable deseo de hacer respirable tan falso y cargado ambiente, nunca marchitan.

Los grupos sociales populares de todo el mundo, y muchas ONGs entre ellos, tenemos el compromiso con nuestro tiempo de mantener la Esperanza en un mundo que arrastra un sistema aparentemente sin salida para muchos seres humanos o incluso para todos.

Hablar éticamente de Desarrollo implica por encima de todo la convicción de que el mismo dejará de serlo si no es compartido por todos los Pueblos y respeta a todas las gentes. Con este convencimiento y tras analizar la realidad, la Educación para el Desarrollo se convierte en una herramienta más, dentro de lo que sería a la vez su fundamentación teórica y práctica: La Cooperación al Desarrollo ampliamente concebida.

Hablar de Cooperación al Desarrollo con los países empobrecidos no debe reducirse a canalizar recursos hacia éstos, a tratar cantidad y volumen de proyectos, ni a exigir tan solo a las instituciones el aumento de las partidas de cooperación. Tampoco, a explicar cómo viven la miseria, pobreza y explotación las personas de otros pueblos.

Si bien es cierto que estas tareas son importantes en una ONGD, desde ENTREPUEBLOS creemos necesario enmarcar nuestras acciones dentro de cinco conceptos:

- En lo económico, RESTITUCION. Los pueblos más favorecidos tenemos la obligación de colaborar en la disminución de los niveles de empobrecimiento creados por un sistema injusto de apropiación y distribución de la riqueza. Esto lo debemos hacer no solo en relación a las partidas presupuestarias de cooperación, sino también -y más importante- cuestionando nuestro modo de vida, es decir, reduciendo el consumo superfluo, objetando fiscalmente el gasto militar o contribuyendo con el $0.7 \%$, y más, de nuestros ingresos. 
- En lo social, SOLIDARIDAD. Debemos apoyar a todos aquellos movimientos que desde distintos niveles, ámbitos y situaciones -tanto en el Norte como en el Sur- trabajan por un presente más digno, equitativo y libre. Es necesario poner el énfasis en las soluciones aportadas por las propias organizaciones sociales de los pueblos empobrecidos a sus situaciones concretas.

- En la educación, EMANCIPACION: entendiéndola según Pablo Freire como "un acto de conocimiento y un proceso de acción trasformadora que se ejerce sobre la realidad", la nuestra y la de ellos. Una educación global y emancipadora o concienciación en el sentido de reorientar el discurso, no en la "sensibilización" de la población de los países del Norte sobre "los problemas del Sur", sino sobre la interdependencia de los problemas entendidos a escala planetaria. Las ONGD debemos de servir para el análisis de las causas de la pobreza económica, política y/o tecnológica.

- En la diferencia, RESPETO -que no tolerancia- frente a aquello que, por diferente, nos es extraño o dudoso. Respeto como una aceptación de lo positivo de la diversidad, de la pluralidad de costumbres, culturas y pueblos. Así, y de forma recíproca, podremos rescatar valores comunes que nos hagan capaces, desde la inter y multiculturalidad, replantear y redefinir un nuevo futuro común más justo y solidario.

- En la necesidad de trasformación, COOPERACION. Es necesario operar conjuntamente, desde los movimientos propios de la sociedad civil, para la transformación -aquí y allá- de las causas y estructuras económicas, sociales y políticas que impiden el derecho y la necesidad de un modelo de vida con desarrollo sostenible, y por tanto más austero para el Norte y más solidario y libre para todos.

Si hubiera que resumir en una frase el objetivo de nuestra cooperación, diríamos que trabajamos en la búsqueda de una Justicia que permita la satisfacción igualitaria para cualquier persona y en cualquier lugar del mundo de los Derechos Humanos.

Nos referimos a derechos individuales y colectivos contemplados en las conocidas Declaraciones de Derechos:

Derecho a una vida digna, a la integridad de la persona, a la sanidad, a la educación, a la vivienda, al trabajo... y nos atrevemos a incluir derechos colectivos reivindicados por muchas culturas, diferentes a la nuestra, pero que podemos considerar igualmente universales, como pueden ser: derecho a la tierra, derecho a un medio ambiente saludable...

Si bien es cierto que el objetivo indicado aquí es utópico, reivindicamos la Utopía; pero la reivindicamos desde la realidad, para conseguir tanto hay que empezar por poco, pero ese poco es igualmente importante.

Vivimos inmersos en un sistema injusto de apropiación y distribución de la riqueza. Consideramos que es un acto de justicia el devolver o restituir a los países del Sur lo que les hemos robado, usurpado y expoliado desde los países del Norte en complicidad con sus propios gobiernos. Nuestro compromiso podríamos resumirlo en algunos ejes principales: 
1. Identificar los mecanismos y actores que están creando el injusto reparto y apropiación de riqueza (BM, FMI, relaciones comerciales injustas, planes de ajuste estructural, deuda externa, tráfico de armas, mercenarios, flujos especulativos de capital, etc.), y denunciarlos.

2. Financiar Proyectos de Desarrollo en los países del Sur.

3. Cuestionar nuestro modo de vida reduciendo el consumo superfluo.

4. Realizar campañas de denuncia y sensibilización sobre las injusticias existentes.

5. Canalizar la participación de todas aquellas personas que quieran colaborar en estas tareas.

En resumen, hay que ir elaborando una alternativa al llamado, actualmente, "Pensamiento único". Afirmar que no es único, e ir pensando juntos un nuevo modelo de Desarrollo.

Nuestra cooperación se concreta en varios campos, en los que según las disponibilidades de cada cual se puede participar de forma activa:

1. Proyectos de Cooperación

2. Difusión

3. Denuncia

4. Brigadas de solidaridad

5. Educación para el Desarrollo:

Entendiendo la educación como ya hemos dicho, según Pablo Freire, como "un acto de conocimiento y un proceso de acción transformadora que se ejerce sobre la realidad". Trabajamos el área de Educación Emancipatoria o Educación para el Desarrollo, tanto desde la educación formal como de la no formal, a través de la elaboración de programas, unidades didácticas, talleres de formación, publicaciones, exposiciones y actividades públicas, con el fin de aportar a la educación integral de las personas la compresión de forma interrelacionada, significativa y crítica de los fenómenos locales, nacionales e internacionales.

La educación para el Desarrollo que realizamos en La Rioja, se basa fundamentalmente en una oferta informativa y formativa a la sociedad, a cuyo carro se incorporan personas con inquietud por la Justicia y la Dignidad de los Pueblos. Así, desarrollamos actividades como: charlas-coloquio, jornadas sobre temas concretos, exposiciones, trípticos y librillos informativos, charlas en institutos, participación en mesas redondas, etc.

Si bien, nuestra trayectoria nos ha llevado a hacer especial hincapié en los países latinoamericanos por ser lo que más conocemos, intentamos tocar otros países y temas de espectro más amplio. Para ello nuestra participación en plataformas conjuntas con otras organizaciones, procuramos que sea activa. Es el caso de plataformas como la del 0,7 o por la condonación de Deuda Externa, entre otras.

Otra faceta en nuestro grupo es la formación interna. Recopilamos material de interés como estudios referentes a la cooperación, determinados conflictos, etc y, en base a ellos, debatimos entre nosotr@s sobre temas variados. 
Pero también consideramos fundamental la denuncia. Es por eso que hacemos actividades como recogida de firmas, o carteladas con intención de remover un poco las conciencias. Fue el caso de la polémica "Mierda veo, mierda quiero" en época navideña o, como hicimos este año, denunciando comparativamente la subida de sueldo que hicieron los políticos con el 0,7 del P.I.B. que la Rioja se comprometió a ofertar para Cooperación al Desarrollo y que no llega siquiera al 0,3 por mucho que se hable engañosamente del 0,7 siempre refiriéndose a montos que no son el PIB.

Pero la información también hay que transmitirla a aquellas personas y medios que tienen cierto poder político o social puesto que son quienes más capacidad de influencia tienen, nos representan a tod@s y por tanto deben ser partícipes de nuestras inquietudes, a la vez que colaboradores en la mejora social.

Por eso es fácil vernos metidos en recorridos urbanos con tal defensor de derechos humanos colombiano, con compañeros indígenas ecuatorianos o con quien en cada momento tengamos oportunidad de trabajar, a fin de hacer llegar sus voces y el origen de los conflictos a radios, diarios, televisiones, ayuntamiento, parlamento, obispado, partidos políticos, sindicatos, organizaciones, etc.

Otra faceta importantísima es la relación directa con los compañeros y compañeras del otro lado del océano. Por ello, todos los años presentamos proyectos de Cooperación al Desarrollo. También llevamos a cabo, no con subvenciones sino con aportaciones particulares, un proyecto de apoyo a un comedor escolar dentro de barrios periféricos bogotanos donde la gente se organiza cada día para hacer su vida más digna.

Es con este país, con Colombia; con el que Entrepueblos-La Rioja tiene establecido un auténtico cordón umbilical. Todos los años viajan riojanos a través nuestro para realizar labores de acompañamiento a organizaciones sociales que defienden, desde distintos campos (sindical, campesino, defensores de Derechos Humanos, Iglesia...) la vida digna de un Pueblo aterrorizado por la violencia de la guerra sucia que el estado ejerce con la escusa de combatir la insurgencia y cuya enorme dosis de Injusticia Social de nuevo enjendra más violencia, esta vez en forma de delincuencia común.

Sin embargo y a raíz de los viajes, la fuerza luchadora de l@s compañer@s colombian@s que cada día arriesgan su vida por el bien común, nos ha impuesto la necesidad de colaborar con ell@s. Por eso, dentro de Entrepueblos-La Rioja, surgió hace ya cuatro años un grupo de trabajo específico con Colombia. Desde él hacemos seguimiento de la realidad diaria del país y de las demandas que nuestr@s compañer@s nos hacen. A partir de ahí y, en coordinación con otros grupos del Estado Español que también colaboran con Colombia, elaboramos líneas de trabajo y actividades tanto conjuntas como particulares en cada zona.

Todas estas actividades sin lugar a dudas nos forman personalmente y en la medida que sentimos la necesidad de compartirlo con más gente para ampliar la fuerza en la lucha por un mundo donde quepamos tod@s. Creemos que esa formación compartida nos llevará para poco a poco a no conformarnos con un Desarrollo para minorías, sino ir descubriendo y exigiendo el verdadero Desarrollo, el que nos pertenece a todos los habitantes del planeta sin excepción. 


\section{Bibliografía}

LEVIN LEAH. 1999. "Derechos humanos: preguntas y respuestas". Ediciones Unesco/Bakeaz.

Amnistía Internacional. 1995. "Educación en Derechos Humanos. Propuestas didácticas". Madrid: Los libros de la catarata.

ARREGI, Ion. 1994. "Voces de Colombia. Mirada a una sociedad urgente". Ed. GAKOA Liburuak.

GIRALDO, Javier y ARREGI, Ion (compilador). 1998. "Colombia. Un Pueblo sentenciado a muerte". Ed. GAKOA Liburuak.

FREIRE, Paulo. 1988. "Pedagogía de la contradicción". Anthropos Editorial del hombre.

FREINET, Celestin. 1986. "Por una escuela del pueblo". Cuadernos de Pedagogía. Editorial Laia.

Revistas y boletines:

Cuadernos de Pedagogía. Febrero 1999.

Gallopinto. Revista del Comité de Solidaridad Internacionalista de Zaragoza. Enero 2000.

Hirugarren Mundua ta Bakea / Paz y Tercer Mundo. Dossier ํㅡํㅜ 5. Itinerarios... de la Educación para el Desarrollo.

Página Abierta. Números 75/1997, 84-88-89/1998, 99/1999, 100/2000.

Cuadernos Bakeaz. Educación para la Paz.

Boletín de Entrepueblos. Número 26 y resto.

Cuadernos de Solidaridad. Edita Entrepueblos.

Educar desde el Interculturalismo-Documentos. Amarú Ediciones. Coordina Entrepueblos. 